\title{
Prognostic genes of breast cancer revealed by gene co-expression network analysis
}

\author{
HUIJIE SHI $^{1}$, LEI ZHANG ${ }^{2}$, YANJUN QU ${ }^{1}$, LIFANG HOU $^{1}$, LING WANG $^{1}$ and MIN ZHENG ${ }^{1}$ \\ ${ }^{1}$ Prenatal Diagnosis Center, The First Affiliated Hospital of Harbin Medical University, \\ Harbin, Heilongjiang 150001; ${ }^{2}$ Department of Pathology, School of Basic Medical Sciences, \\ Harbin Medical University, Harbin, Heilongjiang 150081, P.R. China
}

Received January 6, 2016; Accepted May 26, 2017

DOI: $10.3892 / \mathrm{ol} .2017 .6779$

\begin{abstract}
The aim of the present study was to identify genes that may serve as markers for breast cancer prognosis by constructing a gene co-expression network and mining modules associated with survival. Two gene expression datasets of breast cancer were downloaded from ArrayExpress and genes from these datasets with a coefficient of variation $>0.5$ were selected and underwent functional enrichment analysis with the Database for Annotation, Visualization and Integration Discovery. Gene co-expression networks were constructed with the WGCNA package in R. Modules were identified from the network via cluster analysis. Cox regression was conducted to analyze survival rates. A total of 2,669 genes were selected, and functional enrichment analysis of them revealed that they were mainly associated with the immune response, cell proliferation, cell differentiation and cell adhesion. Seven modules were identified from the gene co-expression network, one of which was found to be significantly associated with patient survival time. Expression status of 144 genes from this module was used to cluster patient samples into two groups, with a significant difference in survival time revealed between these groups. These genes were involved in the cell cycle and tumor protein p53 signaling pathway. The top 10 hub genes were identified in the module. The findings of the present study could advance the understanding of the molecular pathogenesis of breast cancer.
\end{abstract}

\section{Introduction}

Breast cancer is the most common type of cancer in women, accounting for $25 \%$ of all cases (1). Risk factors include lifestyle (including smoking or diet), genetics and medical conditions. A number of treatment methods are now available for

Correspondence to: Dr Min Zheng, Prenatal Diagnosis Center, The First Affiliated Hospital of Harbin Medical University, 23 Youzheng Street, Harbin, Heilongjiang 150001, P.R. China

E-mail: zhnwgehdh@hotmail.com

Key words: breast cancer, functional enrichment analysis, gene co-expression network, hub genes, survival analysis breast cancer, including surgery, radiotherapy, chemotherapy, hormone therapy and targeted therapy. However, certain patients have a poor prognosis and the molecular mechanisms underlying this remain unclear. Prognostic factors include disease stage and grade, recurrence of the disease, and the age and health of the patient.

With advances in technology and the accumulation of research results, certain molecular markers associated with breast cancer have been well studied. Tumor protein p53 mutations are poor prognostic factors in breast cancer (2). MYC proto-oncogene and bHLH transcription factor-driven accumulation of 2-hydroxyglutarate are associated with poor breast cancer prognosis (3). Prostaglandin-endoperoxide synthase 2 expression predicts worse breast cancer prognosis (4). Ki-67 has been associated with disease-free survival, but its prognostic value remains to be validated (5). Matrix metalloproteinase- 8 gene variation may influence breast cancer prognosis and can have an inhibitory effect on cancer metastasis (6). A gene signature involved in tumor-immune interactions may provide a more accurate prognostic tool (7). Zhang et al (8) performed a meta-analysis and demonstrated that overexpression of C-X-C motif chemokine receptor 4 was significantly associated with lymph node status and distant metastasis, indicating poor overall and disease free survival. SRY-box 4 overexpression is a biomarker for malignant status and poor prognosis in breast cancer patients (9). A number of other novel biomarkers have also been also identified, including chromobox homolog 1 (10), HOX transcript antisense intergenic RNA (9) and anterior gradient 3 (11). Nevertheless, more prognostic genes are required to further improve treatment decisions and thus the quality of life of patients with breast cancer.

Microarray technology has been widely used to identify biomarkers of breast cancer $(12,13)$, allowing for the large-scale screening of molecular markers. In the present study, two gene expression datasets were obtained to reveal prognostic genes $(14,15)$. One dataset was used with the aim of identifying genes associated with the distant metastasis of lymph-node-negative primary breast cancer (14); the other was used to identify genes involved in response and survival following taxane-anthracycline chemotherapy in breast cancer (14). The two datasets were combined to construct a gene co-expression network and analyze survival time to identify novel biomarkers associated with breast cancer prognosis. 


\section{Materials and methods}

Raw data and pre-treatment. Two gene expression datasets, GSE2034 (14) and GSE25066 (15), were downloaded from ArrayExpress (https://www.ebi.ac.uk/arrayexpress/). Dataset GSE2034 included 286 breast cancer samples and dataset GSE25066 included 508 breast cancer samples. The two gene expression datasets were obtained using Affymetrix GPL96 platform.

Normalization was performed with rma from the affy package (16) in R (R 3.2.0; https://www.r-project.org/) and then $\log _{2}$ conversion was applied. Probes were mapped onto genes according to annotation files. Probes mapping to the same gene were averaged as the expression level for the gene.

Functional enrichment analysis. Gene Ontology (GO) annotation and pathway enrichment analysis were performed with DAVID (Database for Annotation, Visualization and Integration Discovery; http://david.abcc.ncifcrf.gov/) (17).

Gene co-expression network and modules. The gene co-expression network was constructed with the WGCNA package (18) in R. The adjacency coefficient $a_{i j}$ was calculated as follows:

$$
\begin{gathered}
a_{\mathrm{ij}}=\mathrm{S}_{i j}^{\beta} \\
S_{i j}=\left|\operatorname{cor}\left(x_{i}, x_{j}\right)\right|
\end{gathered}
$$

Where $x_{i}$ and $x_{j}$ are vectors of expression value for gene $i$ and $j$; cor represents the Pearson's correlation coefficient of the two vectors; $a_{i j}$ is the adjacency coefficient and is acquired via exponential transform of $S_{i j}$.

WGCNA method takes topological properties into consideration to identify modules from gene co-expression networks. Therefore, this method not only considers the association between the two connected nodes, but also takes associated genes into account. It calculates the weighting coefficient $W_{i j}$ from $a_{i j}$ as follows:

$$
\begin{aligned}
& W_{i j}=\frac{l_{i j}+a_{i j}}{\min \left\{k_{i}, k_{j}\right\}+1-a_{i j}} \\
& l_{i j}=\sum_{\mathrm{u}} a_{i u} a_{u j}, k_{i}=\sum_{\mathrm{u}} a_{i u}
\end{aligned}
$$

$W_{i j}$ considers the overlap between neighbor genes of genes $i$ and $j$. Modules were identified via hierarchical clustering of the weighting coefficient matrix, $W$.

Survival analysis. Cox regression was performed with hub genes from the modules to identify survival-associated genes, and Kaplan-Meier survival was used to compare the survival time of different groups, which were performed with the Survival package in R (https://cran.r-project. org/web/views/Survival.html). $\mathrm{P}<0.05$ was considered to indicate a statistically significant difference. Pearson's correlation was performed by cor function in R (19).

\section{Results}

Gene expression data. A total of 13,191 genes were identified in the GSE2034 and GSE25066 datasets, for which box plots are presented in Fig. 1. According to the box plots, the average total mRNA expression level in each sample was consistent, indicating that a good performance of normalization was achieved for both datasets.

Functional enrichment analysis. A total of 2,669 genes with coefficient of variation $(\mathrm{CV})>0.5$ were selected. Functional enrichment analysis revealed that they were associated primarily with immune response, cell proliferation, cell differentiation and cell adhesion (Table I).

Prognostic genes. Two gene co-expression networks were constructed for the two datasets by WGCNA (Fig. 2). Seven modules were identified from the network of GSE2034 via hierarchical clustering of the weighting coefficient matrix, $W$ (Fig. 3). The modules were termed the red, blue, green, black, brown, yellow and turquoise modules.

The degree, $k$, for each gene in the module was calculated and the P-value of Cox regression between each gene and survival was also determined. Next, the correlation between $k$ and $-\log _{10}(\mathrm{P})$ was calculated. The yellow module exhibited significant correlation with survival time in dataset

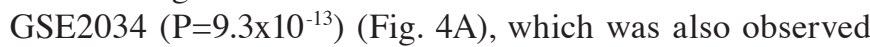
in dataset GSE25066 $\left(\mathrm{P}=9.3 \times 10^{-6}\right)$ (Fig. 4B). Besides, survival-associated genes $(\mathrm{P}<0.05$ in Cox regression) were significantly over-represented in the yellow module in both datasets (Fig. 5). Therefore, the yellow module was considered to be significantly associated with breast cancer patient survival, which should be further investigated to understand the association between survival time and critical gene expression.

The 144 genes from the yellow module were used in the cluster analysis of samples from dataset GSE2034, which separated the patient samples into two groups based on the expression of these genes (Fig. 6). A significant difference in survival time was observed between the two groups $(\mathrm{P}=0.008$; Fig. 7). Functional enrichment analysis indicated that the 144 genes from the yellow module were involved in cell cycle, oocyte meiosis, the tumor protein p53 signaling pathway and progesterone-mediated oocyte maturation (Table II).

The top 10 hub genes from the yellow module were selected (Table III) and included cyclin B2 (CCNB2), ubiquitin-conjugating enzyme $\mathrm{E} 2 \mathrm{C}(\mathrm{UBE} 2 \mathrm{C})$, protein regulator of cytokinesis 1 (PRC1), cell division cycle 20 (CDC20), abnormal spindle microtubule assembly (ASPM), forkhead box M1 (FOXM1), kinesin family member 4A (KIF4A), nucleolar and spindle associated protein 1 (NUSAP1), pituitary tumor-transforming 1 (PTTG1) and centrosomal protein $55 \mathrm{kDa}$ (CEP55). All of these genes were significantly associated with survival time in the two datasets.

\section{Discussion}

Two gene expression datasets of breast cancer were obtained and the 2,669 differentially expressed genes with a CV $>0.5$ were selected. These genes were implicated in the immune response, cell proliferation and cell migration. These functions 
Table I. Top 15 significantly over-represented biological pathways .

\begin{tabular}{llll}
\hline ID & \multicolumn{1}{c}{ Description } & P-value & Adjusted P-value \\
\hline GO:0006955 & Immune response & $2.19 \times 10^{-63}$ & $3.27 \times 10^{-61}$ \\
GO:0006952 & Defense response & $2.15 \times 10^{-57}$ & $2.80 \times 10^{-55}$ \\
GO:0006950 & Response to stress & $1.57 \times 10^{-56}$ & $1.96 \times 10^{-54}$ \\
GO:0007166 & Cell-surface receptor signaling pathway & $1.20 \times 10^{-55}$ & $1.43 \times 10^{-53}$ \\
GO:0008283 & Cell proliferation & $1.06 \times 10^{-49}$ & $1.09 \times 10^{-47}$ \\
GO:0002682 & Regulation of immune system process & $6.12 \times 10^{-42}$ & $4.82 \times 10^{-40}$ \\
GO:0016477 & Cell migration & $7.58 \times 10^{-40}$ & $5.66 \times 10^{-38}$ \\
GO:0045321 & Leukocyte activation & $1.90 \times 10^{-39}$ & $1.32 \times 10^{-37}$ \\
GO:0006954 & Inflammatory response & $3.92 \times 10^{-38}$ & $2.66 \times 10^{-36}$ \\
GO:0048584 & Positive regulation of response to stimulus & $6.10 \times 10^{-38}$ & $4.05 \times 10^{-36}$ \\
GO:0042127 & Regulation of cell proliferation & $1.72 \times 10^{-37}$ & $1.10 \times 10^{-35}$ \\
GO:0030154 & Cell differentiation & $3.01 \times 10^{-34}$ & $1.70 \times 10^{-32}$ \\
GO:0048869 & Cellular developmental process & $2.06 \times 10^{-33}$ & $7.77 \times 10^{-33}$ \\
GO:0007155 & Cell adhesion & $1.11 \times 10^{-32}$ & $4.14 \times 10^{-31}$ \\
GO:0022610 & Biological adhesion & & $4.22 \times 10^{-31}$ \\
\hline
\end{tabular}

Adjusted P-value: Use the multiple comparisons in General Linear Model ANOVA, the adjusted P-value indicates which factor level comparisons within a family of comparisons (hypothesis tests) are significantly different.
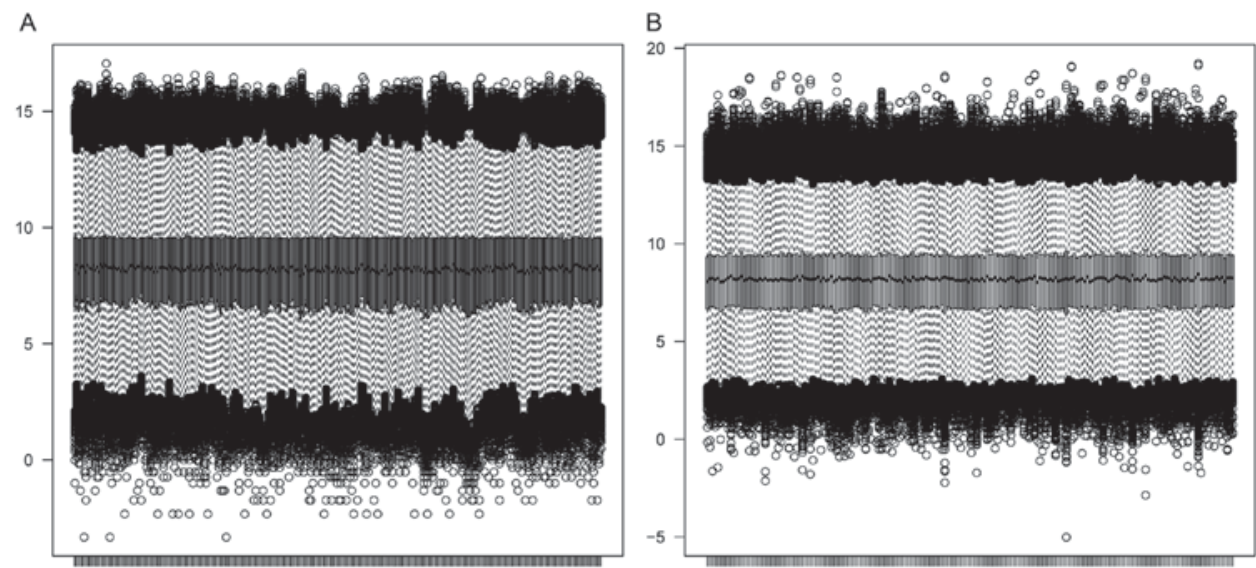

Figure 1. Box plots of normalized gene expression data of two datasets. (A) GSE2034 (286 samples) and (B) GSE25066 (200 samples randomly selected from the total 508 samples). The average total mRNA expression level in each sample was consistent, indicating that a good performance of normalization was achieved. The $\mathrm{x}$-axis represents the gene expression level; the $\mathrm{y}$-axis represents the samples.
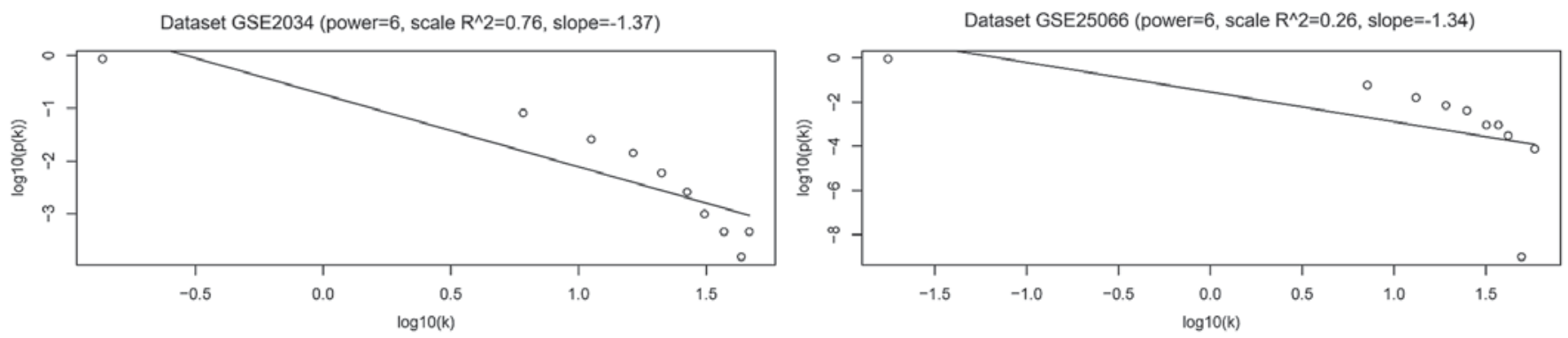

Figure 2. Gene co-expression networks for datasets GSE2034 (left) and GSE25066 (right). The x-axis represents the degree of the node, $k$, while the y-axis represents proportion of genes with degree of $k, p(k)$.

were closely associated with the development and metastasis of cancer. A breast-cancer-specific gene co-expression network was constructed for dataset GSE2034, from which 7 modules were identified. The yellow module was closely associated with 

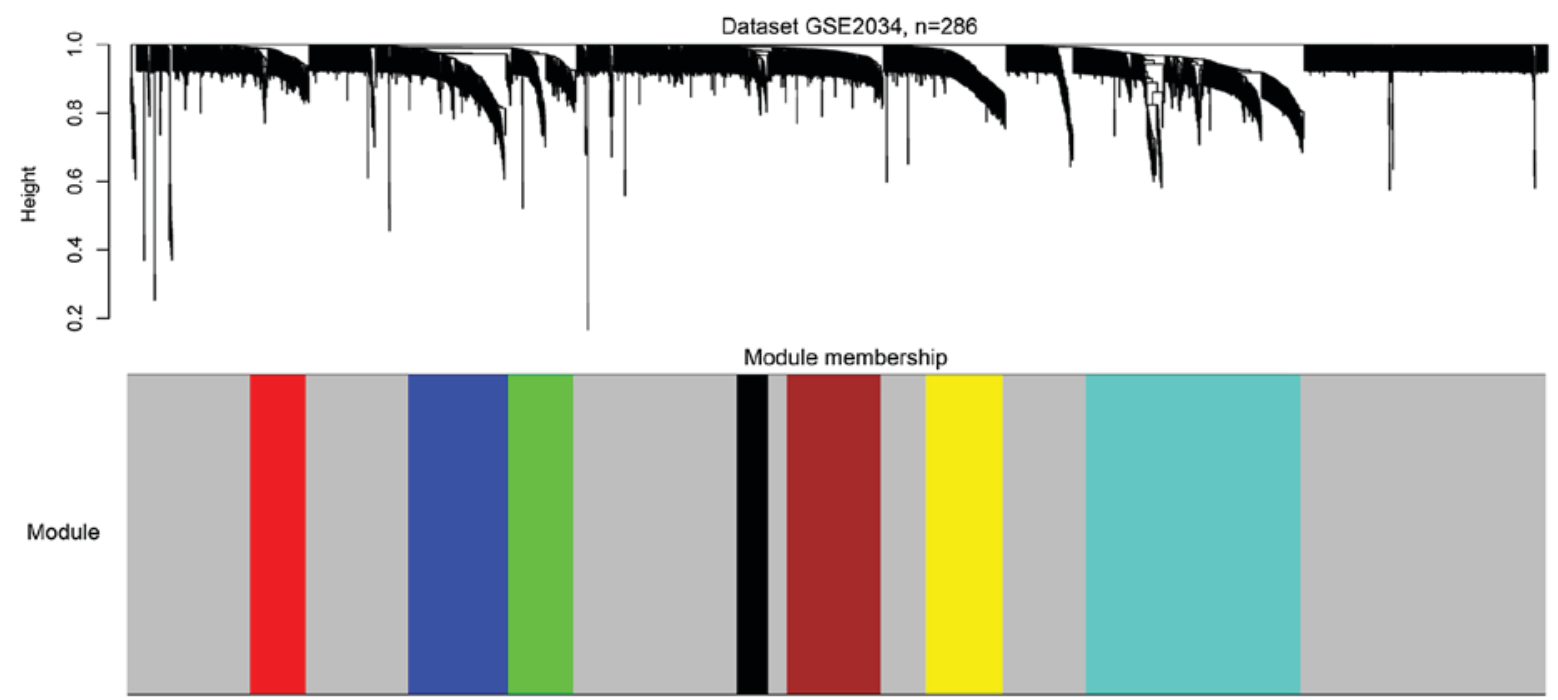

Figure 3. Seven modules identified from the gene co-expression network. Cluster analysis result is shown above and module identification shown below.
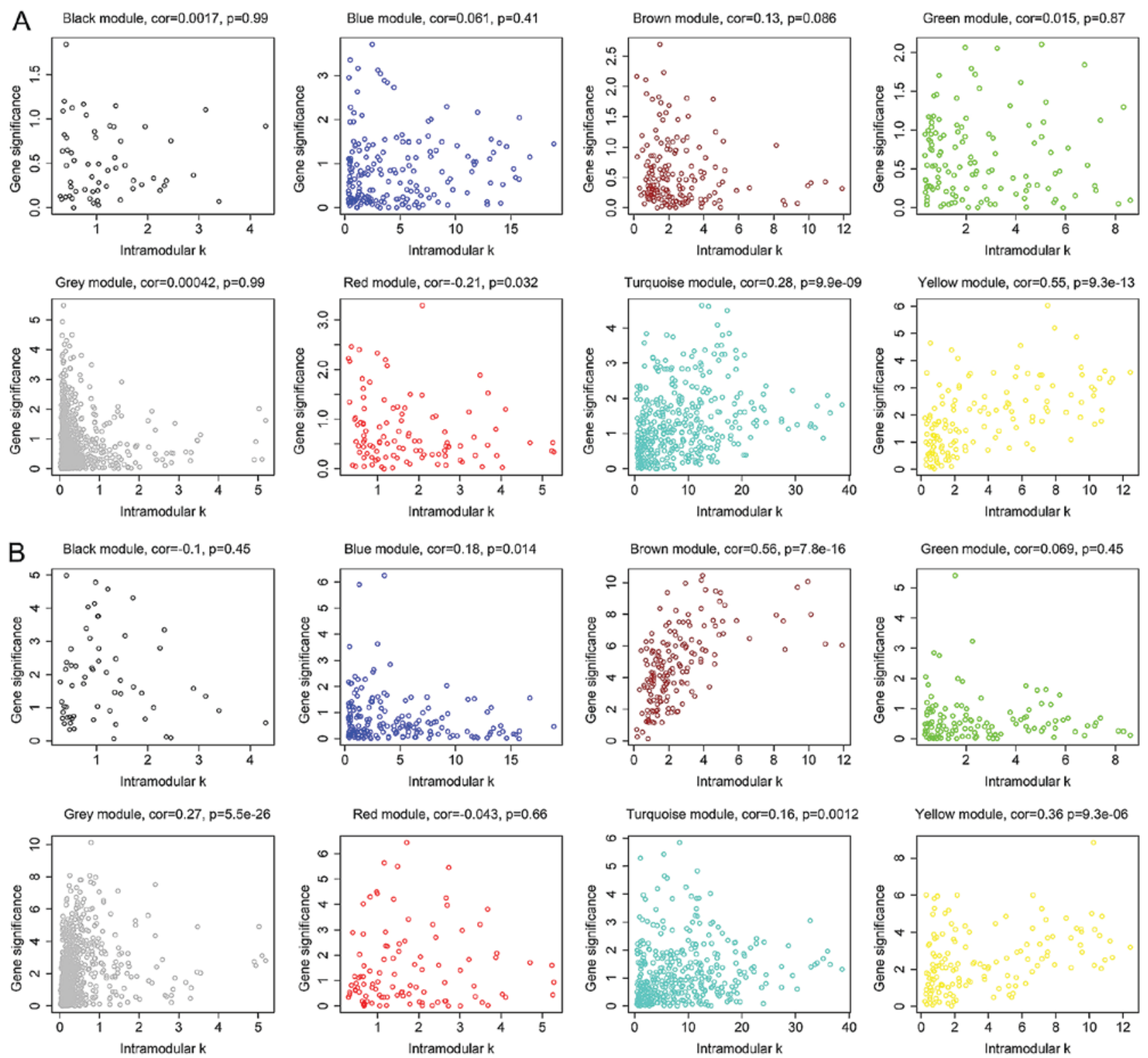

Figure 4. Scatter plots of the degree and P-value of Cox regression in datasets (A) GSE2034 and (B) GSE25066. The x-axis indicates the degree of regression, the $y$-axis indicates the P-value. Each circle represents a gene. 


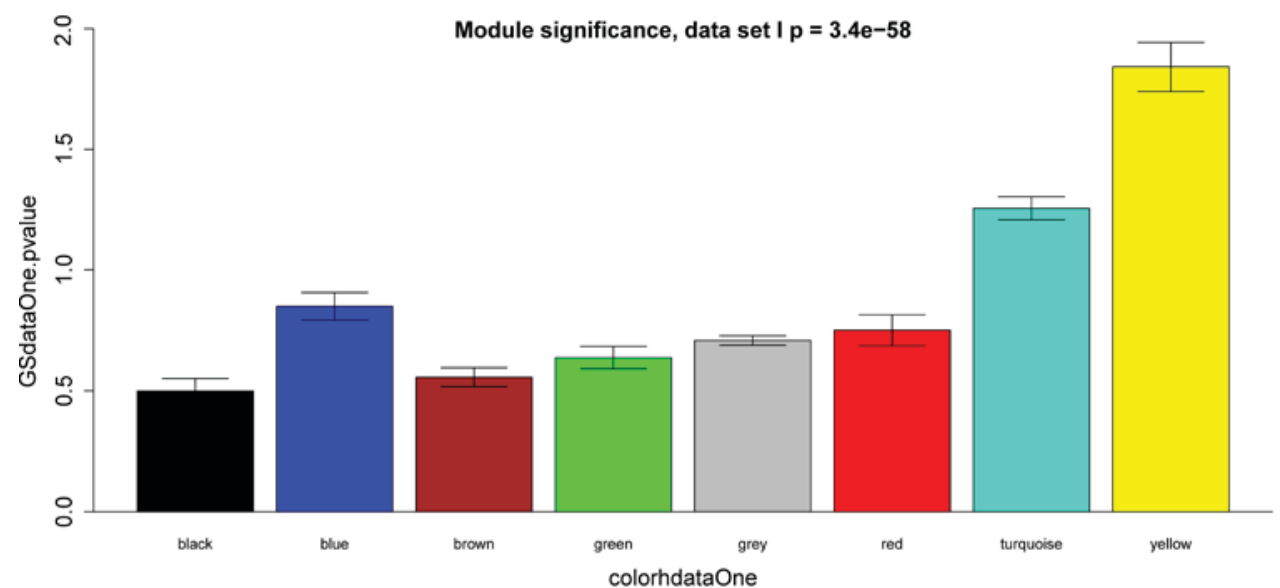

Figure 5. Survival-associated genes in each module. The x-axis indicates the module, the y-axis indicates the significance of over-representation.
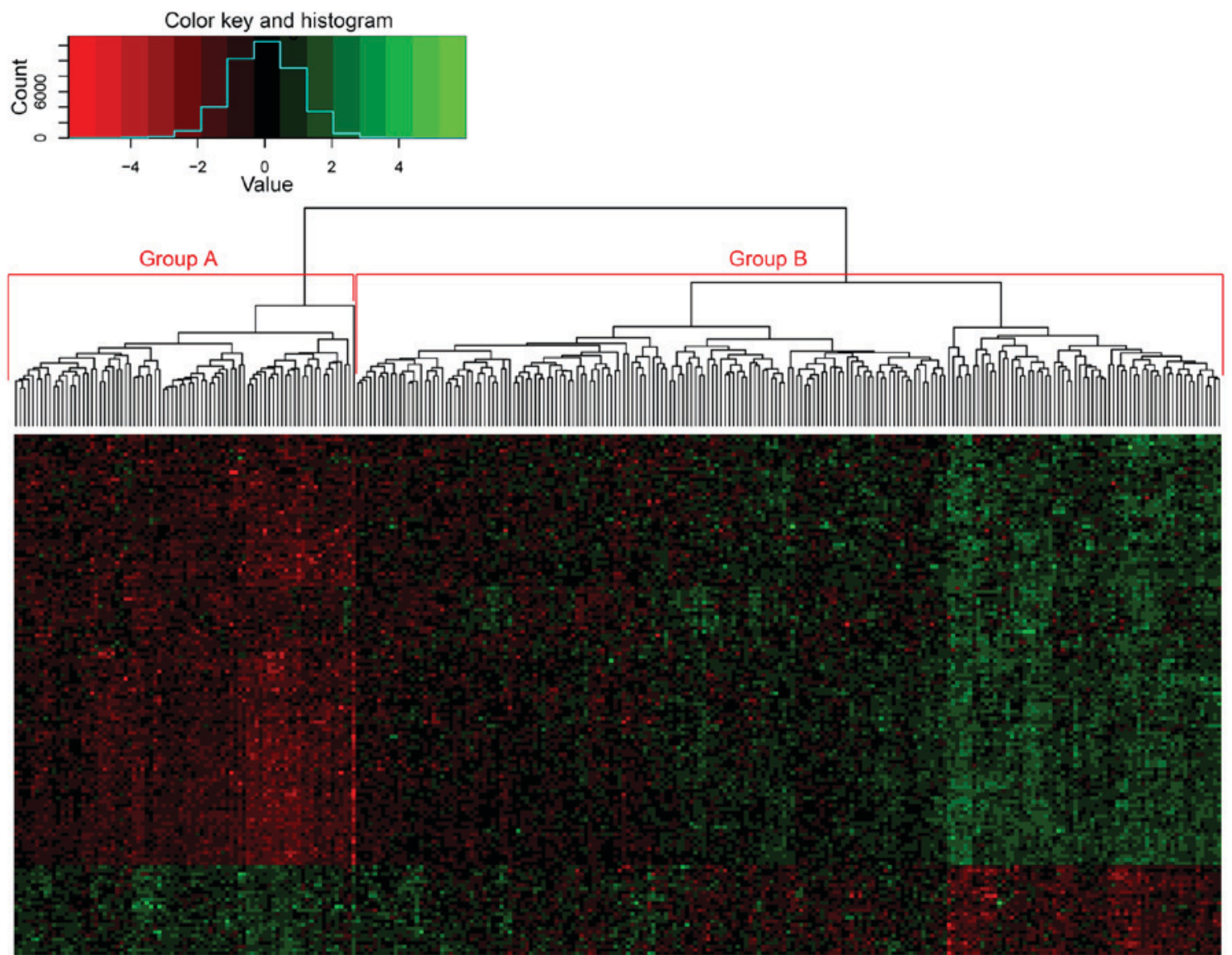

Figure 6. Cluster analysis using the degree of expression of 144 survival-associated genes for the samples in the GSE2034 dataset.

survival time and, as such, the 144 genes from yellow module were investigated further. These genes were primarily involved in the cell cycle and tumor protein p53 signaling pathway. The top 10 hub genes were identified in the yellow module, all of which were associated with poor patient prognosis.

The majority of the 10 critical genes in the yellow module are associated with the cell cycle. CCNB 2 is an essential component of the cell-cycle regulatory machinery (20). Elevated CCNB2 expression in invasive breast cancer is associated with unfavorable clinical outcomes (21). UBE2C is required for the degradation of mitotic cyclins and for cell-cycle progression, and is involved in cancer progression. UBE2C is highly expressed in breast microcalcification lesions (22). The prognostic value of UBE2C has been validated in several studies (23-25). microRNA-196a post-transcriptionally upregulates UBE2C and promotes cell proliferation in breast cancer (26). Inhibition of UBE2C reduces proliferation and sensitizes breast cancer cells to radiotherapy and chemotherapy (27), suggesting that it could serve as a potential therapeutic target. CDC20 is a regulatory protein in the cell cycle. Overexpression of CDC20 
Table II. KEGG pathways enriched in the 144 genes of the yellow module.

\begin{tabular}{llll}
\hline ID & \multicolumn{1}{c}{ Description } & P-value & Adjusted P-value \\
\hline hsa04110 & Cell cycle & $5.22 \times 10^{-18}$ & $3.13 \times 10^{-17}$ \\
hsa04114 & Oocyte meiosis & $2.17 \times 10^{-9}$ & $6.50 \times 10^{-9}$ \\
hsa04115 & p53 signaling pathway & $2.46 \times 10^{-5}$ & $4.91 \times 10^{-5}$ \\
hsa04914 & Progesterone-mediated oocyte maturation & $9.19 \times 10^{-5}$ & $1.38 \times 10^{-4}$ \\
\hline
\end{tabular}

p53, tumor protein p53. Adjusted P-value: Using multiple comparisons in a general linear model analysis of variance, the adjusted P-value indicates which factor level comparisons within a family of comparisons (hypothesis tests) are significantly different.

Table III. Top 10 hub genes in the yellow module.

\begin{tabular}{|c|c|c|c|c|c|}
\hline Dataset & Gene name & Coefficient & P-value & $k_{\text {Total }}$ & $k_{\text {Within }}$ \\
\hline \multirow[t]{10}{*}{ GSE2034 } & CCNB2 & 0.3640 & 0.0003 & 14.7998 & 12.4392 \\
\hline & PRC1 & 0.3868 & 0.0005 & 12.9603 & 11.3677 \\
\hline & UBE2C & 0.4281 & 0.0006 & 14.1236 & 11.2433 \\
\hline & ASPM & 0.3442 & 0.0002 & 12.9467 & 10.9328 \\
\hline & CDC20 & 0.2339 & 0.0065 & 14.6847 & 10.7527 \\
\hline & FOXM1 & 0.1988 & 0.0168 & 13.7352 & 10.7131 \\
\hline & CEP55 & 0.3691 & 0.0004 & 12.6988 & 10.6131 \\
\hline & KIF4A & 0.2648 & 0.0217 & 12.1095 & 10.3165 \\
\hline & NUSAP1 & 0.3931 & 0.0012 & 11.7988 & 10.2885 \\
\hline & PTTG1 & 0.4027 & 0.0019 & 12.4981 & 10.2449 \\
\hline \multirow[t]{10}{*}{ GSE25066 } & CCNB2 & 0.323932 & 0.3239 & 0.0006 & 9.4109 \\
\hline & PRC1 & 0.276034 & 0.2760 & 0.0023 & 6.6109 \\
\hline & UBE2C & 0.381925 & 0.3819 & 0.0003 & 6.1036 \\
\hline & ASPM & 0.207911 & 0.2079 & 0.0031 & 4.9210 \\
\hline & CDC20 & 0.329027 & 0.3290 & 0.0000 & 8.5936 \\
\hline & FOXM1 & 0.170967 & 0.1710 & 0.0091 & 5.9345 \\
\hline & CEP55 & 0.304415 & 0.3044 & 0.0002 & 6.3694 \\
\hline & KIF4A & 0.568168 & 0.5682 & 0.0001 & 3.1945 \\
\hline & NUSAP1 & 0.270014 & 0.2700 & 0.0061 & 6.7332 \\
\hline & PTTG1 & 0.791755 & 0.7918 & 0.0000 & 4.0029 \\
\hline
\end{tabular}

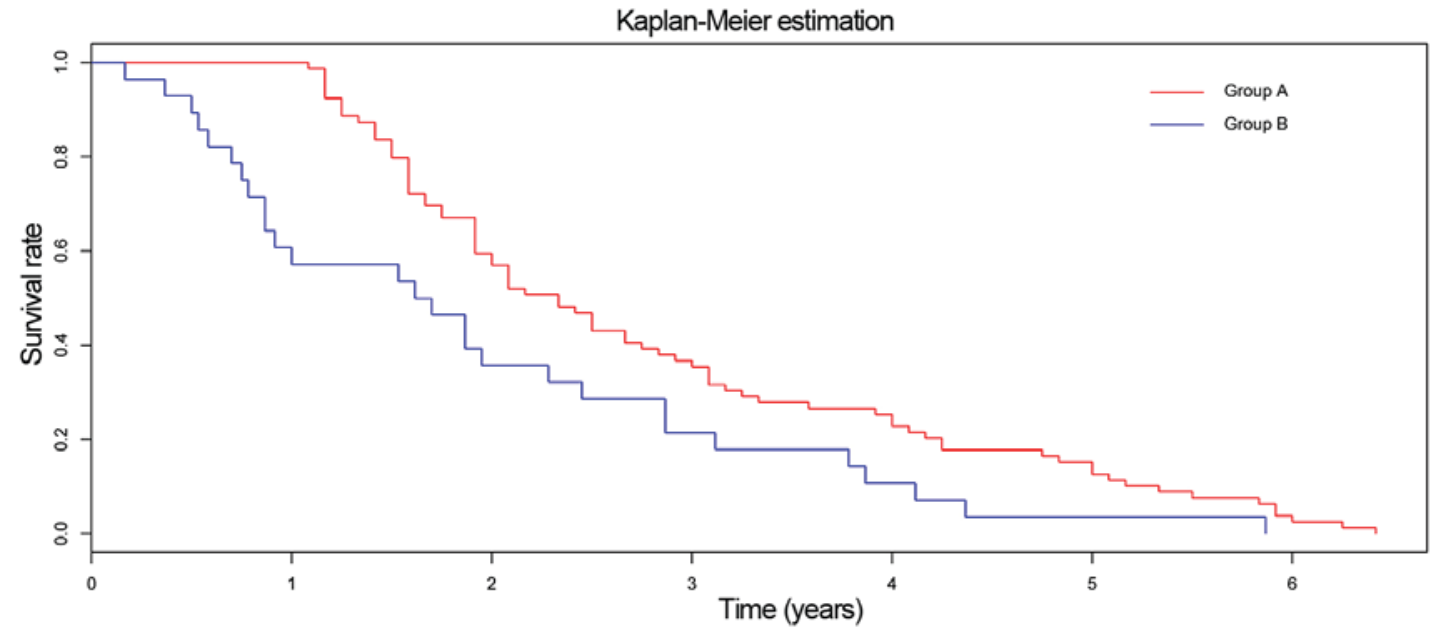

Figure 7. Survival curves for the two groups of breast cancer patient samples clustered according to expression of the 144 genes. 
predicts short-term breast cancer survival (22). ASPM is essential for normal mitotic spindle function and is a marker for vascular invasion, early recurrence and poor prognosis of hepatocellular carcinoma (28). Increased ASPM expression is also associated with enhanced tumor grade and lower survival rates of epithelial ovarian cancer (29). A significant correlation between the expression of the CCNB2 and ASPM proteins is reported (21), which may serve a role in the development of breast cancer.

FOXM1 is a transcriptional activator involved in cell proliferation, which is a downstream target and marker of HER 2 overexpression in breast cancer (30). FOXM1 is implicated in the proliferation, migration and invasion of breast cancer cells $(31,32)$ and serves a role in chemotherapy resistance $(33,34)$. KIF4A is an ATP-dependent microtubule-based motor protein that is involved in the intracellular transport of membranous organelles. KIF4A is implicated in doxorubicin-induced apoptosis in breast cancer cells (35). NUSAP1 may be involved in tumorigenesis and in the processes of invasion and progression of breast cancer (36); it influences the DNA damage response by controlling the protein levels of BRCA1 (37). PTTG1 exhibits tumorigenic activity in vivo and is highly expressed in various tumors; it is associated with endocrine therapy resistance in breast cancer (38). PTTG1 may promote tumor malignancy via the epithelial-to-mesenchymal transition and the expansion of the cancer stem cell population (39). CEP55 is also involved in breast cancer progression (40), possibly exerting an oncogenic function via regulation of the phosphoinositide-3 kinase/protein kinase B pathway and midbody fate (41).

PRC1 encodes a protein involved in cytokinesis, specifically the polarization of parallel microtubules, whose expression level changes markedly in the different phases of the cell cycle. PRC1 has been demonstrated to be a substrate of several cyclin-dependent kinases (CDKs); its alternative splicing results in multiple transcript variants $(42,43)$. Although PRC1 serves an important role in the cell cycle, its role in breast cancer remains unclear. The results of the present study indicate that the role of PRC1 in the pathogenesis of breast cancer necessitates further study.

Gene co-expression network analysis revealed several genes of prognostic significance in breast cancer. The majority of these genes have been validated by previous studies; however, the function of certain critical genes identified by gene co-expression network analysis in breast cancer remains unclear, thus providing targets for further studies. These prospective studied may disclose novel biomarkers or provide targets for breast cancer therapies.

\section{References}

1. McGuire S: World Cancer Report 2014. Geneva, Switzerland: World health organization, international agency for research on cancer, WHO Press, 2015. Adv Nutr 7: 418-419, 2016.

2. Takahashi S, Moriya T, Ishida T, Shibata H, Sasano H, Ohuchi N and Ishioka C: Prediction of breast cancer prognosis by gene expression profile of TP53 status. Cancer Sci 99: 324-332, 2008.

3. Atsushi T, Nagireddy P, Prachi M, Mathé EA, Dorsey TH, Yi M, Wallace TA, Issaq HJ, Zhou M, Killian JK, et al: MYC-driven accumulation of 2-hydroxyglutarate is associated with breast cancer prognosis. J Clin Invest 124: 398-412, 2014.
4. Holmes MD, Chen WY, Schnitt SJ, Collins L, Colditz GA, Hankinson SE and Tamimi RM: COX-2 expression predicts worse breast cancer prognosis and does not modify the association with aspirin. Breast Cancer Res Treat 130: 657-662, 2011.

5. Kontzoglou K, Palla V, Karaolanis G, Karaiskos I, Alexiou I, Pateras I, Konstantoudakis K and Stamatakos M: Correlation between Ki67 and Breast Cancer Prognosis. Oncology 84: 219-225, 2013.

6. Decock J, Long JR, Laxton RC, Shu XO, Hodgkinson C, Hendrickx W, Pearce EG, Gao YT, Pereira AC, Paridaens R, et al: Association of matrix metalloproteinase-8 gene variation with breast cancer prognosis. Cancer Res 67: 10214-10221, 2007.

7. Manjili MH, Najarian K and Wang XY: Signatures of tumor-immune interactions as biomarkers for breast cancer prognosis. Future Oncol 8: 703-711, 2012.

8. Zhang Z, Ni C, Chen W, Wu P, Wang Z, Yin J, Huang J and Qiu F: Expression of CXCR4 and breast cancer prognosis: A systematic review and meta-analysis. Bmc Cancer 14: 49, 2014.

9. Zhang L, Song X, Wang X, Xie Y, Wang Z, Xu Y, You X, Liang Z and Cao H: Circulating DNA of HOTAIR in serum is a novel biomarker for breast cancer. Breast Cancer Res Treat 152: 199-208, 2015.

10. Lee YH, Liu X, Qiu F, O'Connor TR, Yen Y and Ann DK: Correction: HP1 $\beta$ is a biomarker for breast cancer prognosis and PARP inhibitor therapy. PLoS One 10: e0124853, 2015.

11. Garczyk S, von Stillfried S, Antonopoulos W, Hartmann A, Schrauder MG, Fasching PA, Anzeneder T, Tannapfel A, Ergönenc Y, Knüchel R, et al: Agr3 in breast cancer: Prognostic impact and suitable serum-based biomarker for early cancer detection. PLoS One 10: e0122106, 2015.

12. Brennan DJ, Kelly C, Rexhepaj E, Dervan PA, Duffy MJ and Gallagher WM: Contribution of DNA and tissue microarray technology to the identification and validation of biomarkers and personalised medicine in breast cancer. Cancer Genomics Proteomics 4: 121-134, 2007.

13. Miecznikowski JC, Wang D, Liu S, Sucheston L and Gold D: Comparative survival analysis of breast cancer microarray studies identifies important prognostic genetic pathways. BMC Cancer 10: 573, 2010.

14. Wang Y, Klijn JG, Zhang Y, Sieuwerts AM, Look MP, Yang F, Talantov D, Timmermans M, Meijer-van Gelder ME, Yu J, et al: Gene-expression profiles to predict distant metastasis of lymph-node-negative primary breast cancer. Lancet 365: 671-679, 2005.

15. Hatzis C, Pusztai L, Valero V, Booser DJ, Esserman L, Lluch A, Vidaurre T, Holmes F, Souchon E, Wang H, et al: A genomic predictor of response and survival following taxane-anthracycline chemotherapy for invasive breast cancer. JAMA 305: 1873-1881, 2011.

16. Gautier L, Cope L, Bolstad BM and Irizarry RA: affy-analysis of Affymetrix GeneChip data at the probe level. Bioinformatics 20: 307-315, 2004.

17. Dennis G Jr, Sherman BT, Hosack DA, Yang J, Gao W, Lane HC and Lempicki RA: DAVID: Database for annotation, visualization and integrated discovery. Genome Biol 4: P3, 2003.

18. Langfelder P and Horvath S: WGCNA: An R package for weighted correlation network analysis. BMC Bioinformatics 9: $559,2008$.

19. Becker RA, Chambers JM and Wilks AR: The New S Language. Wadsworth \& Brooks/Cole, Monterey, 1988.

20. Nasmyth K: Viewpoint: Putting the cell cycle in order. Science 274: 1643-1645, 1996.

21. Shubbar E, Kovács A, Hajizadeh S, Parris TZ, Nemes S, Gunnarsdóttir K, Einbeigi Z, Karlsson P and Helou K: Elevated cyclin B2 expression in invasive breast carcinoma is associated with unfavorable clinical outcome. Bmc Cancer 13: 1,2013

22. Chou CP, Huang NC, Jhuang SJ, Pan HB, Peng NJ, Cheng JT, Chen CF, Chen JJ and Chang TH: Ubiquitin-conjugating enzyme UBE2C is highly expressed in breast microcalcification lesions. PLoS One 9: e93934, 2014.

23. Psyrri A, Kalogeras KT, Kronenwett R, Wirtz RM, Batistatou A, Bournakis E, Timotheadou E, Gogas H, Aravantinos G, Christodoulou $\mathrm{C}$, et al: Prognostic significance of UBE2C mRNA expression in high-risk early breast cancer. A Hellenic Cooperative Oncology Group (HeCOG) Study. Ann Oncol 23: 1422-1427, 2012 
24. Psyrri D, Kronenwett R, Timotheadou E, Wirtz RM, Onyenadum A, Pentheroudakis GE, Papadimitriou CA, Razis E, Economopoulos T and Fountzilas G: Evaluation of the prognostic value of UBE2C mRNA levels in early breast cancer. J Clinical Oncol 28 (15 suppl): S10570, 2010.

25. Loussouarn D, Campion L, Leclair F, Campone M, Charbonnel C, Ricolleau G, Gouraud W, Bataille R and Jézéquel P: Validation of UBE2C protein as a prognostic marker in node-positive breast cancer. Br J Cancer 101: 166-173, 2009.

26. Han Q, Zhou C, Liu F, Xu G, Zheng R and Zhang X: MicroRNA-196a post-transcriptionally upregulates the UBE2C proto-oncogene and promotes cell proliferation in breast cancer. Oncol Rep 34: 877-883, 2015.

27. Rawat A, Gopal G, Selvaluxmy G and Rajkumar T: Inhibition of ubiquitin conjugating enzyme UBE2C reduces proliferation and sensitizes breast cancer cells to radiation, doxorubicin, tamoxifen and letrozole. Cell Oncol (Dordr) 36: 459-467, 2013.

28. Lin SY, Pan HW, Liu SH, Jeng YM, Hu FC, Peng SY, Lai PL and Hsu HC: ASPM is a novel marker for vascular invasion, early recurrence, and poor prognosis of hepatocellular carcinoma. Clin Cancer Res 14: 4814-4820, 2008.

29. Brüning-Richardson A, Bond J, Alsiary R, Richardson J, Cairns DA, McCormack L, Hutson R, Burns P, Wilkinson N, Hall GD, et al: ASPM and microcephalin expression in epithelial ovarian cancer correlates with tumour grade and survival. Br J Cancer 104: 1602-1610, 2011

30. Francis RE, Myatt SS, Krol J, Hartman J, Peck B, McGovern UB, Wang J, Guest SK, Filipovic A, Gojis O, et al: FoxM1 is a downstream target and marker of HER2 overexpression in breast cancer. Int J Oncol 35: 57-68, 2009.

31. Ahmad A, Wang Z, Kong D, Ali S, Li Y, Banerjee S, Ali R and Sarkar FH: Foxm1 down-regulation leads to inhibition of proliferation, migration and invasion of breast cancer cells through the modulation of extra-cellular matrix degrading factors. Breast Cancer Res Treat 122: 337-346, 2010.

32. Yang C, Chen H, Tan G, Gao W, Cheng L, Jiang X, Yu L and Tan Y: FOXM1 promotes the epithelial to mesenchymal transition by stimulating the transcription of slug in human breast cancer. Cancer Lett 340: 104-112, 2013.

33. Kwok JM, Peck B, Monteiro LJ, Schwenen HD, Millour J, Coombes RC, Myatt SS and Lam EW: FOXM1 confers acquired cisplatin resistance in breast cancer cells. Mol Cancer Res 8: $24-34,2010$
34. Millour J, Constantinidou D, Stavropoulou AV, Wilson MS, Myatt SS, Kwok JM, Sivanandan K, Coombes RC, Medema RH, Hartman J, et al: FOXM1 is a transcriptional target of ERalpha and has a critical role in breast cancer endocrine sensitivity and resistance. Oncogene 29: 2983-2995, 2010.

35. Wang H, Lu C, Li Q, Xie J, Chen T, Tan Y, Wu C and Jiang J: The Role of Kif4A in doxorubicin-induced apoptosis in breast cancer cells. Mol Cells 37: 812-818, 2014

36. Colak D, Nofal A, Albakheet A, Nirmal M, Jeprel H, Eldali A, Al-Tweigeri T, Tulbah A, Ajarim D, Malik OA, et al: Age-specific gene expression signatures for breast tumors and cross-species conserved potential cancer progression markers in young women. PLoS One 8: e63204, 2013.

37. Kotian S, Banerjee T, Lockhart A, Huang K, Catalyurek UV and Parvin JD: NUSAP1 influences the DNA damage response by controlling BRCA1 protein levels. Cancer Biol Ther 15: 533-543, 2014.

38. Ghayad SE, Vendrell JA, Bieche I, Spyratos F, Dumontet C, Treilleux I, Lidereau R and Cohen PA: Identification of TACC1, NOV, and PTTG1 as new candidate genes associated with endocrine therapy resistance in breast cancer. J Mol Endocrinol 42: 87-103, 2009.

39. Yoon CH, Kim MJ, Lee H, Kim RK, Lim EJ, Yoo KC, Lee GH, Cui YH, Oh YS, Gye MC, et al: PTTG1 promotes tumor malignancy via epithelial to mesenchymal transition and expansion of cancer stem cell population. J Biol Chem 287: 19516-19527, 2012.

40. Jeffery J, Sinha D, Srihari S, Kalimutho M and Khanna KK: Beyond cytokinesis: The emerging roles of CEP55 in tumorigenesis. Oncogene 35: 683-690, 2016.

41. Subramanian R, Wilson-Kubalek EM, Arthur CP, Bick MJ, Campbell EA, Darst SA, Milligan RA and Kapoor TM: Insights into antiparallel microtubule crosslinking by PRC1, a conserved nonmotor microtubule binding protein. Cell 142: 433-443, 2010.

42. Shrestha S, Wilmeth LJ, Eyer J and Shuster CB: PRC1 controls spindle polarization and recruitment of cytokinetic factors during monopolar cytokinesis. Mol Biol Cell 23: 1196-1207, 2012.

43. van den Boom V, Rozenveld-Geugien M, Bonardi F, Malanga D, van Gosliga D, Heijink AM, Viglietto G, Morrone G, Fusetti F, Vellenga E and Schuringa JJ: Nonredundant and locus-specific gene repression functions of PRC1 paralog family members in human hematopoietic stem/progenitor cells. Blood 121: 2452-2461, 2013. 